\title{
Snowflake shaped high-conductivity inserts for heat transfer enhancement
}

\author{
H.C. Konan, E. Cetkin* \\ Izmir Institute of Technology, Department of Mechanical Engineering, Urla, Izmir 35430, Turkey
}

\section{A R T I C L E I N F O}

\section{Article history:}

Received 29 June 2018

Received in revised form 13 August 2018

Accepted 15 August 2018

Available online 22 August 2018

\section{Keywords:}

Heat transfer enhancement

Fins

Constructal Theory

Snowflake

\begin{abstract}
A B S T R A C T
Here, we show numerically how thermal resistance in a two-dimensional domain with a point heat source can be reduced with embedded high-conductivity snowflake shaped pathways. The external shape of the domain is square, and its boundaries are heat sink. The geometry of the inserted pathways which corresponds to the minimum $T_{\max }$ was uncovered with the consideration of Constructal Theory, i.e. the constructal design. In the first assembly, number of mother (big) fins was uncovered as the area fraction increases. The results of the first assembly indicate that the increase in number of mother fins does not increase heat transfer after a limit number for the fins. After uncovering the mother pathway geometry corresponding to the minimum $T_{\max }$, the daughter (small) fins inserted at the tip of them, i.e. second assembly. In the second assembly, the fin ratios, small fin location and angle were discovered when the area fraction is fixed. In addition, in the third assembly, larger daughter fins were attached to mother fins. The results of the second and third assemblies document what should be the geometric length scales and the number of daughter fins in order to minimize $T_{\max }$. The constructal design uncovered is similar to the shape of snowflakes. Therefore, the results also uncover snowflakes correspond to the designs with minimum thermal conductivity, i.e., not mimicking the nature but understanding it with physics.
\end{abstract}

(C) 2018 Elsevier Ltd. All rights reserved.

\section{Introduction}

While the size of electronic equipment decreasing, the number of components and their process capability in those devices are being increased. Therefore, dissipation of heat from the systems while keeping the temperature under a limit temperature becomes more challenging [1]. In order to satisfy the cooling requirement, miniaturization should be violated in convective cooling mechanisms as they require additional space for working fluid, piping and equipment. Whereas, no additional requirement exists for conductive heat transfer. Therefore, conductive heat transfer mechanism becomes more advantageous in miniaturized designs. Bejan [2] stated that conductive pathways are very influential to enhance heat transfer if they are optimized with the consideration of Constructal Theory.

Constructal law was stated by Adrian Bejan in 1996 as "For a finite-size flow system to persist in time (to live), its configuration must change in time such that it provides easier and easier access to its current." The Constructal law can be viewed as a guide to uncover the configurations of natural systems and to create new

\footnotetext{
* Corresponding author.

E-mail address: erdalcetkin@gmail.com (E. Cetkin).
}

configurations for engineering systems [3]. Constructal law is applicable in many distinct fields from biology to transportation [4-7].

Furthermore, the literature documents that the thermal resistance of a domain can be minimized with insertion of highconductivity pathways under the guidance of Constructal law. For instance, Bejan [2] indicated that the configuration of the pathways should be tree-shaped for minimum thermal resistance in a heat generating domain. Ledezma et al. [8] stated the number of branches and their thickness vary depending on the complexity of configuration during optimization. Almogbel and Bejan [9] also documented that there should be a spacing in between the low conductivity material and tip of the pathway in order to acquire minimum thermal resistance. Cetkin and Oliani [10] obtained asymmetric tree-shaped pathways with minimum thermal resistance for non-uniformly heat generated domain. They uncovered the design of the high-conductivity pathway is analogous to the design of roots where the water source is non-uniformly distributed. On the other hand, the literature also shows the design parameter optimizations for specific designs. Lorenzini et al. [11] documented the design of non-uniform X-shaped conductive pathways which correspond to minimum thermal resistance. Hajmohammadi et al. [12-14] documented the optimum forkshaped, V-shaped and Phi-Psi shaped inserts. Horbach et al. [15] 


\section{Nomenclature}

A $\quad$ area $\left[\mathrm{m}^{2}\right]$

$k \quad$ thermal conductivity $\left[\mathrm{W} \mathrm{m}^{-1} \mathrm{~K}^{-1}\right.$ ]

$t_{f} \quad$ thickness of mother fin $[\mathrm{m}]$

$L_{f} \quad$ length of mother fin [m]

$L \quad$ length of square $[\mathrm{m}]$

$m$ number of mother fins

n vector normal to solid-solid interface

$\mathrm{T}$ temperature $[\mathrm{K}]$

$q^{\prime \prime} \quad$ heat flux $\left[\mathrm{W} \mathrm{m}^{-2}\right]$

$\mathrm{x}, \mathrm{y} \quad$ spatial coordinates

Greek letters

$\phi \quad$ volume fraction

$\alpha \quad$ angle between small fins

\begin{tabular}{ll}
\multicolumn{2}{l}{ Subscripts } \\
b & big \\
h & high \\
f & fin \\
l & low \\
max & maximum \\
opt & optimized parameter \\
s & small
\end{tabular}

Superscripts

i index of mesh independency test documented the optimum design of Y-shaped conductive pathways. Feng et al. [16] uncovered the design parameters of optimum "+" shaped high-conductivity pathways to minimize thermal resistance. Eslami [17] documented the thermal performance of Vshaped pathway in a rectangular heat generating domain. You et al. [18] documented optimum configurations of constant and variable cross-sectional pathways in a non-uniform triangular heat generating domain. Lorenzini et al. [19-20] uncovered the effect of the thermal contact resistance on the optimization of I-shaped and T-shaped pathways. In addition, the various constructal fin shapes were documented in the literature [21-27].

Since 1951 scientists have classified snowflake shapes. First, they classified 10 different snowflake shapes [28]. Today, 121 classes exist for snow crystals and solid precipitation particles [29]. In addition, the current literature focuses on snowflake formation and creating new models in order to understand snowflake formation [30-31]. Furthermore, the current literature shows the usage of snowflake shapes to develop more efficient engineering systems [32-33]. Bejan et al. [34] uncovered analytically the solidifying materials should have spherical section in the center of the nucleation site with attached needle-like structure, i.e. snowflake shaped, because this design facilitates the flow of heat toward thermal equilibrium in a more effective manner.

Here, we document the how the fin shape should be altered to minimize thermal resistance in between a point source and a conductive domain. The volume of fins was fixed, and the thermal resistance was decreased with only varying the design under the guidance of Constructal law. The constructal design which is corresponding to the minimum thermal resistance is similar to a specific type of snowflake. We documented the number of mother and daughter fins, their locations, their dimensions, and angle in between the fins in the domain to obtain minimum $T_{\max }$. Here, the design was not dictated as the design of a snowflake as literature focuses. The design is free to evolve, and it evolves to a snowflake design to minimize the resistance to its flow (i.e., heat).

\section{Model}

Consider a two-dimensional domain where heat is generated by a point heat source, the size of $\pi \times R^{2}$. The heat is generated with constant heat flux, $q^{\prime \prime}$. The external shape of the domain is a square with the scale of L. In the domain there are high-conductivity pathways, which are fins, in order to minimize $T_{\max }$. The fins with high thermal conductivity $k_{h}$ are rectangular which are embedded around the heat source. The rest of the domain is composed of low thermal conductivity material with low thermal conductivity $k_{l}$. The area of external shape $\left(A_{s}\right)$ is fixed. Otherwise, fin area $\left(A_{f}\right)$ and fin ratio $\left(t_{f} / L_{f}\right)$ may change. The outer surface of the square domain with length scale of $\mathrm{L}$ the heat sink with $273 \mathrm{~K}$. The other boundary condition is constant surface heat flux $\left(\partial T / \partial \theta=q^{\prime \prime}\right)$ at the circle surface.

In addition to them, for the sake of simplicity heat transfer occurs in the steady state. The materials are isotropic with constant material properties. With this in mind, the heat transfer energy equations were solved simultaneously by using a finite element software, COMSOL Multiphysics 5.0 [35], respectively.

$k_{l}\left(\frac{\partial^{2} T}{\partial x^{2}}+\frac{\partial^{2} T}{\partial y^{2}}\right)=0$

$k_{h}\left(\frac{\partial^{2} T}{\partial x^{2}}+\frac{\partial^{2} T}{\partial y^{2}}\right)=0$

The heat flux continuity between high and the low conductivity material is,

$k_{l}\left(\frac{\partial T}{\partial n}\right)=k_{h}\left(\frac{\partial T}{\partial n}\right)$

where $\mathrm{n}$ is the normal vector to the interface of high and the low conductivity material.

\section{Method}

Consider radius of the point heat source is $0.01 \mathrm{~m}$ with $1 \mathrm{~W} / \mathrm{m}^{2}$ heat flux. The length of the square is $1 \mathrm{~m}$, and the area of the square domain was fixed through the text, so is the area fraction of fins. Thicknesses and lengths were calculated depending on number of fins and volume fraction. Area fraction $(\phi)$ is the ratio of fin area divided by the area of square domain.

$\phi=\frac{A_{f}}{A_{s}}=\frac{m \times L_{f} \times t_{f}}{L \times L}$

where $m$ is the number of fins.

Firstly, there are four symmetrical placed equilaterals spacing at the perimeter of the heat source of radius $0.01 \mathrm{~m}$, while $t_{f} / L_{f}=0.1$ and $\phi$ was varied in between 0.001 and 0.01 .

Unstructured mesh with quadratic shape functions were used through the study. In order to uncover when the results become mesh independent, i.e. not a function of mesh size, mesh independency test was performed. The criterion is $\left|\left(T_{\max }^{i}-T_{\max }^{i+1}\right) / T_{\max }^{i}\right|<$ $5 \times 10^{-6}$ for mesh dependency. Table 1 uncovers that the criterion was satisfied with the mesh number becomes greater than 4000 
Table 1

Mesh independency results.

\begin{tabular}{|c|c|c|c|c|}
\hline & $\phi$ & $\begin{array}{l}\text { Number of } \\
\text { elements }\end{array}$ & $T_{\max }[\mathrm{K}]$ & Error \\
\hline \multirow{12}{*}{$\frac{t_{f}}{L_{f}}=0.1$} & \multirow[t]{3}{*}{0.001} & 1450 & 274.354550 & - \\
\hline & & 3476 & 274.357288 & $9.97953 \mathrm{E}-06$ \\
\hline & & 5088 & 274.357348 & $2.18217 \mathrm{E}-07$ \\
\hline & \multirow[t]{3}{*}{0.002} & 1474 & 274.218492 & - \\
\hline & & 2810 & 274.220093 & $5.83651 \mathrm{E}-06$ \\
\hline & & 4960 & 274.220299 & $7.53896 \mathrm{E}-07$ \\
\hline & \multirow[t]{3}{*}{0.004} & 1236 & 274.065818 & - \\
\hline & & 2810 & 274.067420 & $5.84307 \mathrm{E}-06$ \\
\hline & & 4704 & 274.067530 & $4.00885 \mathrm{E}-07$ \\
\hline & \multirow[t]{3}{*}{0.006} & 1092 & 273.973381 & - \\
\hline & & 1964 & 273.974989 & $5.86758 \mathrm{E}-06$ \\
\hline & & 4048 & 273.975983 & $3.63006 \mathrm{E}-06$ \\
\hline
\end{tabular}

for various volume fractions. Because the mesh is unstructured, even the mesh properties defined as the same, number of the mesh elements vary due to change in the area fraction.

In order to validate current numerical approach, the results were compared with the results of published literature. Table 2 documents the results of Ref. [9] and the relative error between them. The relative error is less than $0.4 \%$. Therefore, the results in the current study are coherent with results in Ref. [9].

The design of high thermal conductivity pathways corresponding to the minimum peak temperature for given set of conditions is called as the constructal design, and as the conditions change it would also be changed, i.e. one constructal design exists for each design conditions. Therefore, the constructal designs correspond to optimal designs in the range of values used. Here we adopt the exhaustive search method such as in Refs. [36-37] in order to uncover constructal design for a specific area fraction.

\subsection{First assembly}

The first assembly corresponds to the design with only mother pathways attached to a heat source at the center as shown in Fig. 1.

Table 2

Validation test results.

\begin{tabular}{llll}
\hline $\mathrm{k}$ & $T_{\max }$ in Ref. [9] & $T_{\max }$ in current study & Relative error (\%) \\
\hline 10 & 0.374893 & 0.37607 & 0.313956 \\
30 & 0.224812 & 0.22519 & 0.168140 \\
100 & 0.157219 & 0.15744 & 0.140568 \\
300 & 0.135924 & 0.13612 & 0.144198 \\
1000 & 0.128236 & 0.12842 & 0.143485 \\
\hline
\end{tabular}

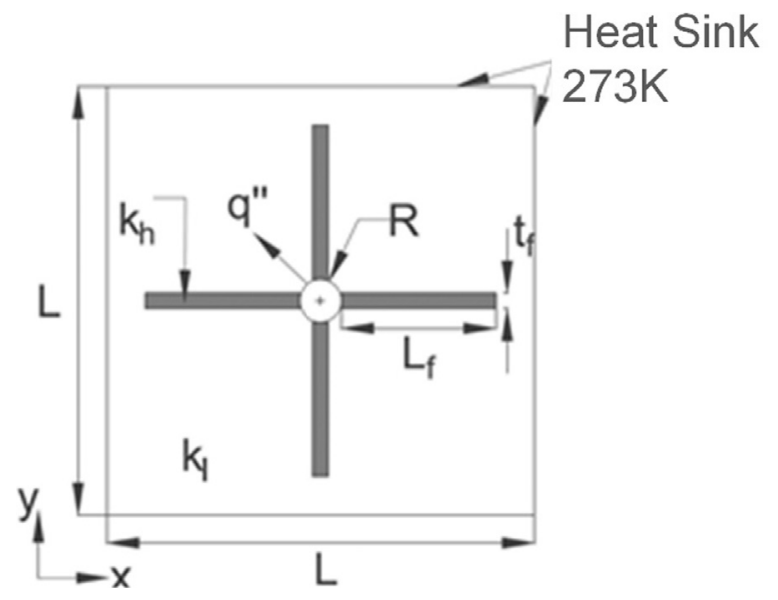

Fig. 1. The general view of the domain.
The fins were placed with equal distance at the perimeter of heat source. Area fraction $(\phi)$ varied from 0.001 to 0.01 , but fin ratio $\left(t_{f} / L_{f}\right)$ was constant and equal to 0.1 in the simulations to obtain number of mother fins corresponding to the minimum peak temperature. Fig. 2 indicates that while increasing $\phi, T_{\max }$ decreases for all numbers of fin number. However, 4 number of fins corresponds to greater $T_{\max }$ value than both 6 and 8 number of mother fins. This corresponds to first extremum where the spacing in between the fins is big enough to increase the thermal resistance in low conductivity domain. $T_{\max }$ value becomes the same for 6 and 8 number of mother fins when $\phi=0.004$, below that $T_{\max }$ is minimum with 8 fins and above that it is minimum with 6 fins. These results uncover the second extremum (the spacing in between fins is short enough for thermal boundary layer to overlap) with 8 number of mother fins after $\phi=0.004$. Here, we select the 6 number of mother fins for the constructal design even though the thermal resistance is minimum with 8 fins when $\phi<0.004$. The reasons of these are; very small difference in between the $T_{\max }$ values for 6 and 8 fins when $\phi<0.004$, and 6 number of fins correspond to the smallest $T_{\max }$ for the rest of the surveyed $\phi$ values. Therefore, the second level of branches will be inserted at the tip of 6 fins.

\subsection{Second assembly}

Fig. 1 shows that in the first assembly high conductivity branches are connected with constant heat flux domain located in the center. The number of the identical branches and their area fraction affects the thermal resistance which inversely proportional to the $T_{\max }$ as shown in Fig. 2. In addition, Ref. [3] showed that thermal resistance can be minimized with addition of daughter high-conductivity pathways (small) at the tip of mother (big) pathways for different boundary conditions and size. They have also uncovered the numbers of daughter pathways should be more than the mother pathways. Therefore, the effect of inserting additional pathways with relatively small thickness to the mother pathways was also discussed. The transition from one level of branch to two levels was uncovered, i.e. when the bifurcation should be. During all the studies the volume of the domains were fixed. In addition, the geometry was defined with three distinct fin ratios which are big fin ratio (BFR), small fin ratio (SFR) and fin ratio (FR). They are defined as:

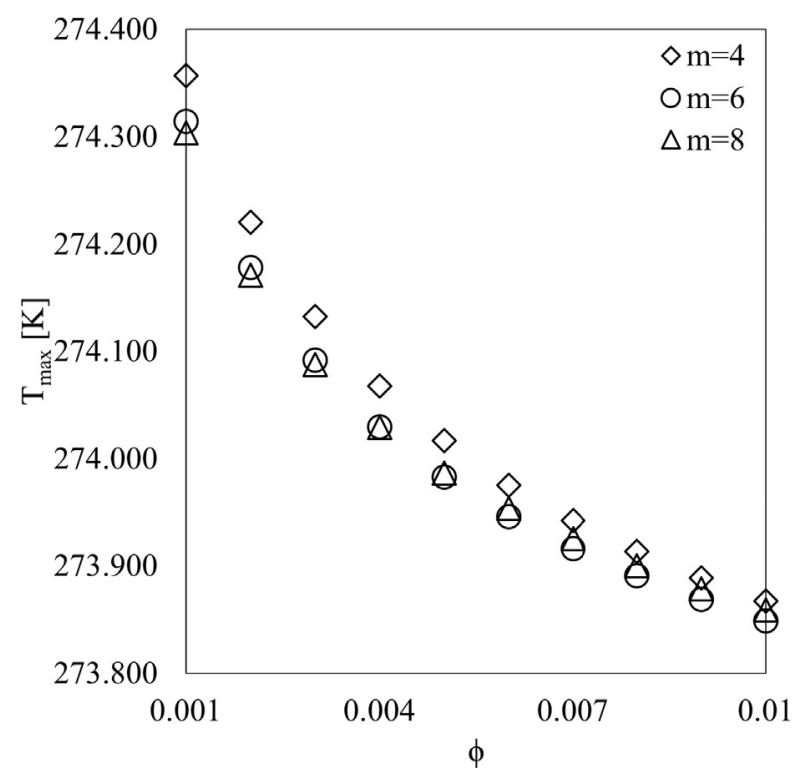

Fig. 2. $T_{\max }$ relative to $\phi$ for various number of mother fins. 
$B F R=\frac{t_{b}}{L_{b}}, S F R=\frac{t_{s}}{L_{s}}, F R=\frac{L_{s}}{L_{b}}$

In the simulations of additional fins area fraction $(\phi)$ was constant, which was equal to 0.001. $\phi$ was fixed to limit the number of simulations during the design parameter optimizations with exhaustive search method. The lengths and thicknesses of fins are shown in Fig. 3.

\subsection{One daughter fin addition}

After deciding the number of mother fins, for further reductions in thermal resistance, daughter (small) fins are attached to the tip of mother fins. In this assembly, one small fin was attached to the tip of each mother fins in the domain as shown in Fig. 3. $\phi$ is 0.001 , and it was fixed where the distinct fin ratios, BFR, SFR and FR, were free to vary. $\phi$ is the ratio of the area covered by the fin geometry divided by the area of the square domain. For one daughter fin addition it becomes

$\phi=\frac{A_{f}}{A_{s}}=\frac{m \times L_{b} \times t_{b}+m \times L_{s} \times t_{s}}{L \times L}$

Furthermore, it will not be defined for other cases because it is trivial. BFR and SFR were varied from 0.01 to 0.1 , and FR were varied from 0.1 to 1 . Here the sequence is as follows, $S F R_{o p t}$ was found firstly with initial FR and BFR values as shown in Fig. 4. Then, $F R_{o p t}$ was decided with $S F R_{\text {opt }}$ and initial BFR value as shown in Fig. 5. Lastly, $B F R_{o p t}$ was obtained with $S F R_{\text {opt }}$ and $F R_{\text {opt }}$, as shown in Fig. 6.

Figs. 4-6 show that there are fin ratios yielding minimum peak temperature for addition of one small fins. Here, Fig. 4 shows that $S F R_{\text {opt }}$ is equal to 0.07 . Fig. 5 shows that $F R_{\text {opt }}$ is 0.3 . In addition, Fig. 6 shows that $B F R_{\text {opt }}$ is 0.02 , and $T_{\max }$ is lower than $T_{\max }$ in Fig. 2 when $\phi$ is 0.001 . Comparison of Figs. 6 and 2 uncovers that the optimized design parameter with one daughter fin attached to each mother fins (Fig. 6 with $\phi=0.001$ ) corresponds to the thermal resistance value of $\phi=0.002$ in Fig. 2. This result is essential because it uncovers that the thermal resistance can be decreased with design alteration instead of high-conductivity material volume twice.

\subsection{Two daughter fins addition}

Next, consider two daughter fins are attached to the tip of each mother fin. First, two small fins were attached to the tip of the big fins. However, the thermal resistance did not decrease in this case. Then, the second fin was attached to the perimeter of the first small fin in order to see its effect. Here, one of the small fin was placed with an angle $\left(10^{\circ}\right)$ at the tip of the big fin which is shown

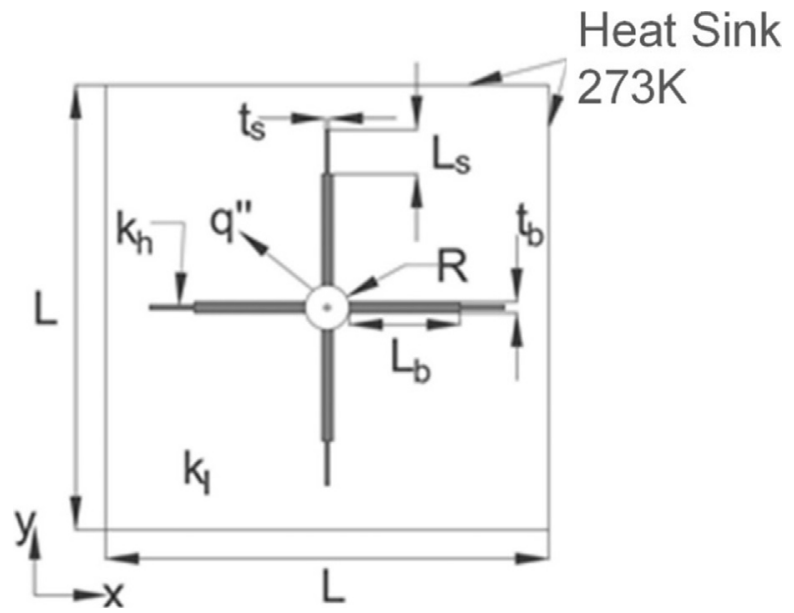

Fig. 3. The domain with additional branches.

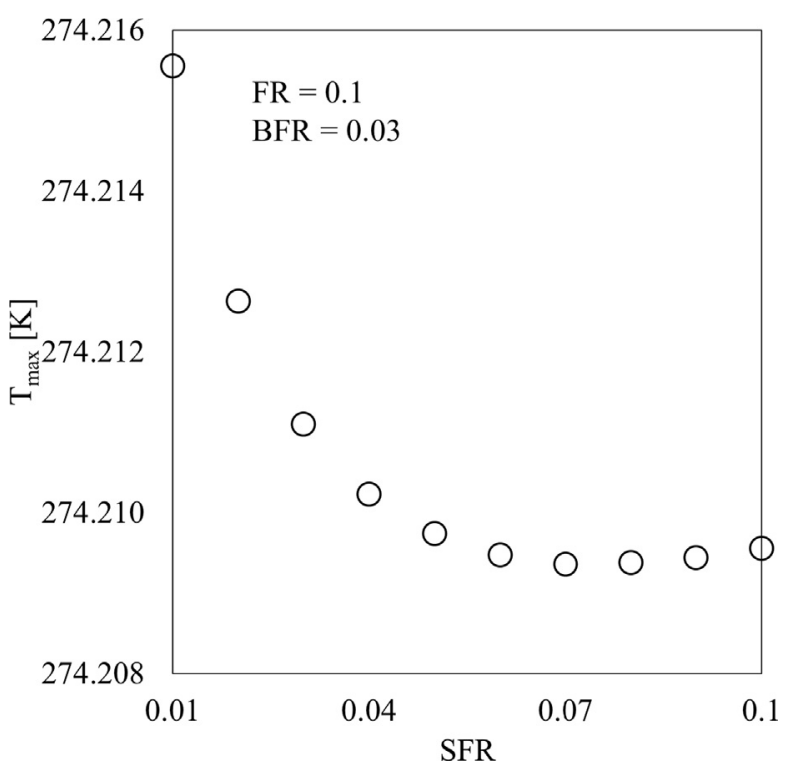

Fig. 4. $T_{\max }$ relative to $\mathrm{SFR}$ for $\mathrm{BFR}=0.03$ and $\mathrm{FR}=0.1$.

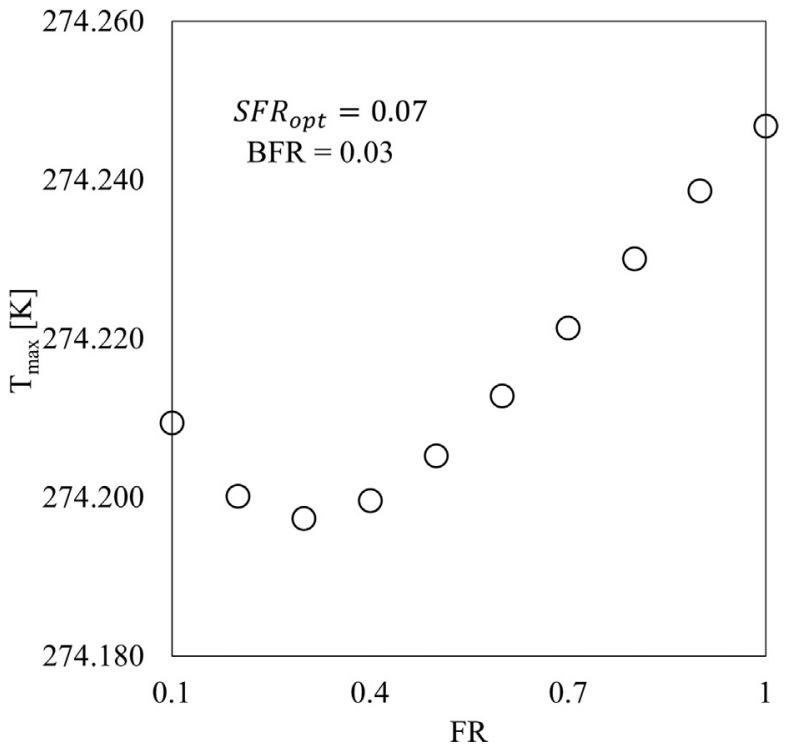

Fig. 5. $T_{\max }$ relative to FR for $\mathrm{BFR}=0.03$ and $S F R_{\text {opt }}=0.07$.

in Fig. 7. Furthermore, the location for the second small fin was surveyed along $L_{s}$. Fig. 8 shows that there is a location where $T_{\max }$ is minimum, which is $0.7 \times L_{s}$. Thus, the second additional fins were placed at this point, and the values for SFR, FR and BFR were uncovered for this fin position. This result may look unexpected. However, as a snowflake growing the thickness of each branch increases, and the thickness is smaller at the tip. Fig. 8 shows this should be the case and if the thickness of the tip of the fin and daughter fin thickness are the same. Then, the position of bifurcation should also be located at a point where is $0.7 \times L_{s}$.

Figs. 9, 10 and 11 show the $S F R_{\text {opt }}, F R_{\text {opt }}$ and $B F R_{\text {opt }}$ corresponding to the minimum $T_{\max }$ exists, respectively. Here, the length scales are $S F R_{\text {opt }}=0.07, F R_{\text {opt }}=0.2$ and $B F R_{\text {opt }}=0.02$.

\subsection{Three daughter fins addition}

Next, consider the addition of third small fins, which are symmetrical to the second small fins as shown Fig. 12. The length 


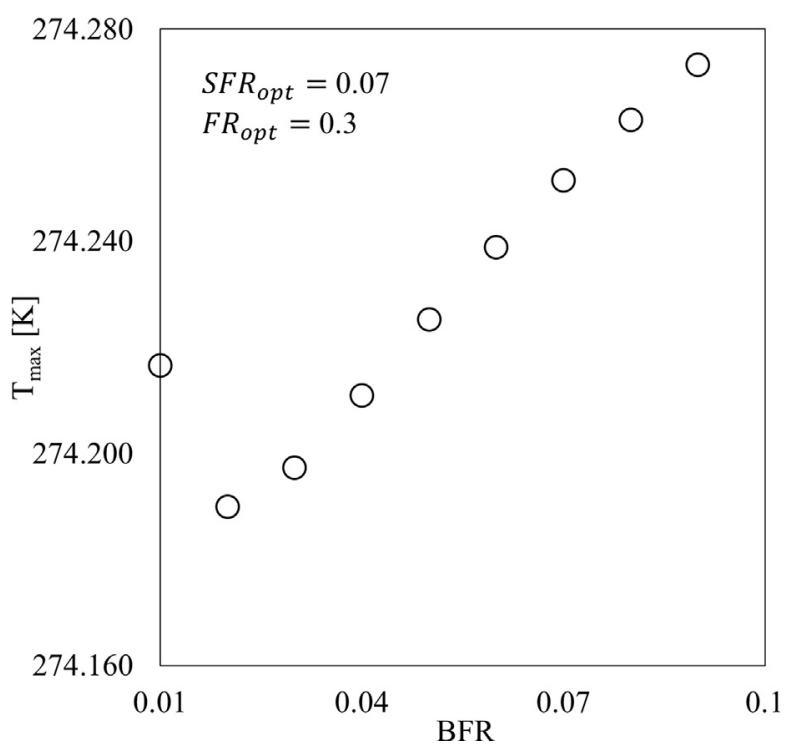

Fig. 6. $T_{\max }$ relative to $B F R$ for $S F R_{o p t}=0.07$ and $F R_{o p t}=0.3$.

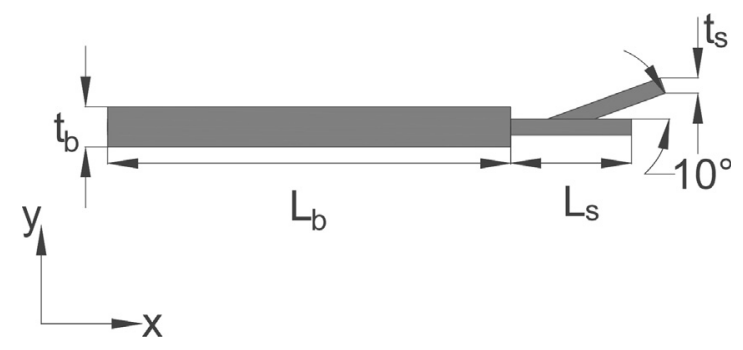

Fig. 7. Placement of the second daughter (small) fin.

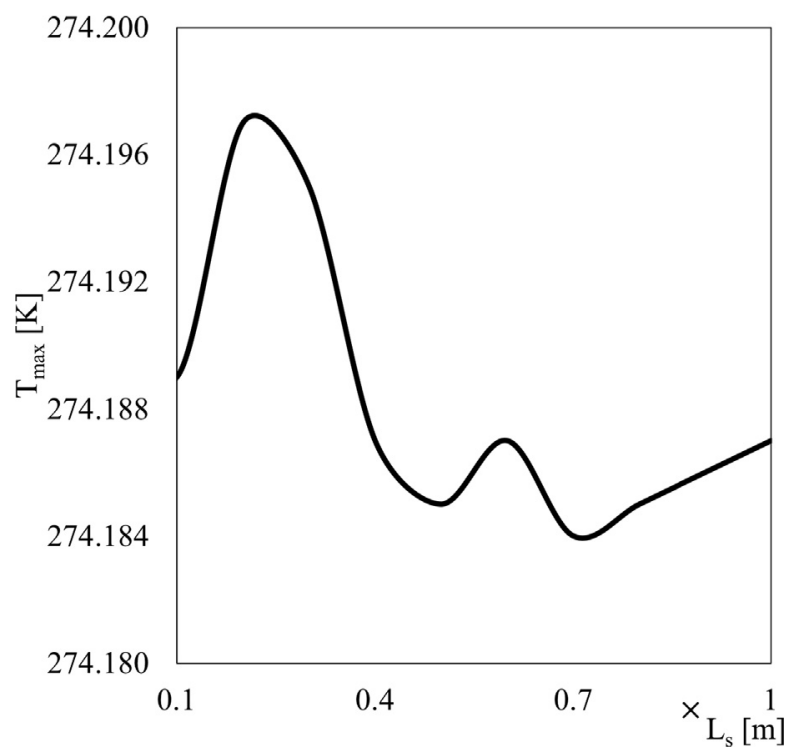

Fig. 8. The effect of location on the peak temperature for the second fins.

scales are uncovered in this section similar fashion to the two small fins addition section.

Figs. 13-15 indicate the fin ratios for adding three small fins. $S F R_{o p t}$ is 0.02 , and it is less than $S F R_{\text {opt }}$ values in the previous two daughter fin additions, which are 0.07 for both of them. In addition,

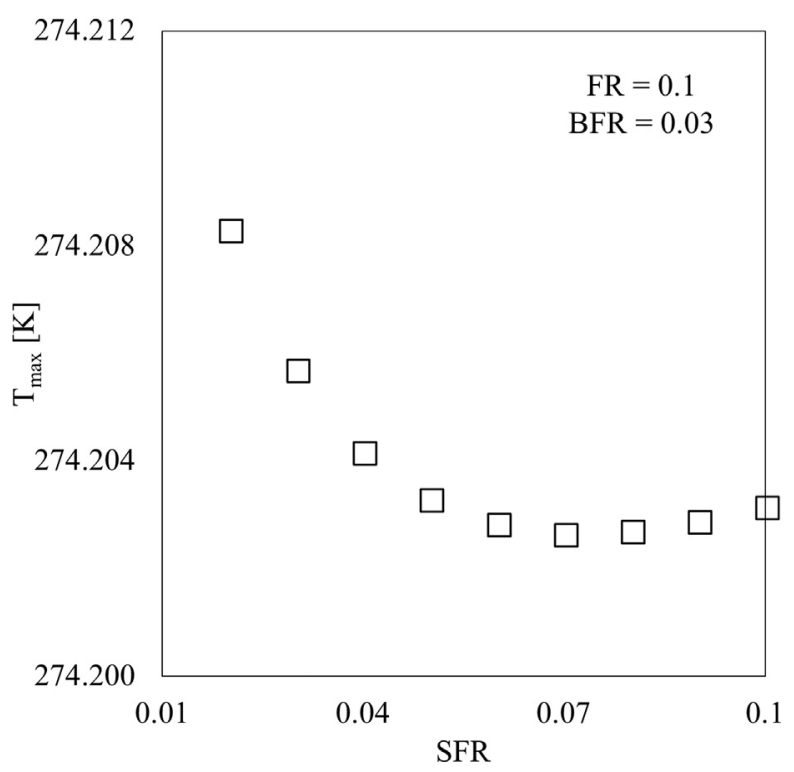

Fig. 9. $T_{\max }$ relative to $\mathrm{SFR}$ for $\mathrm{BFR}=0.03$ and $\mathrm{FR}=0.1$.

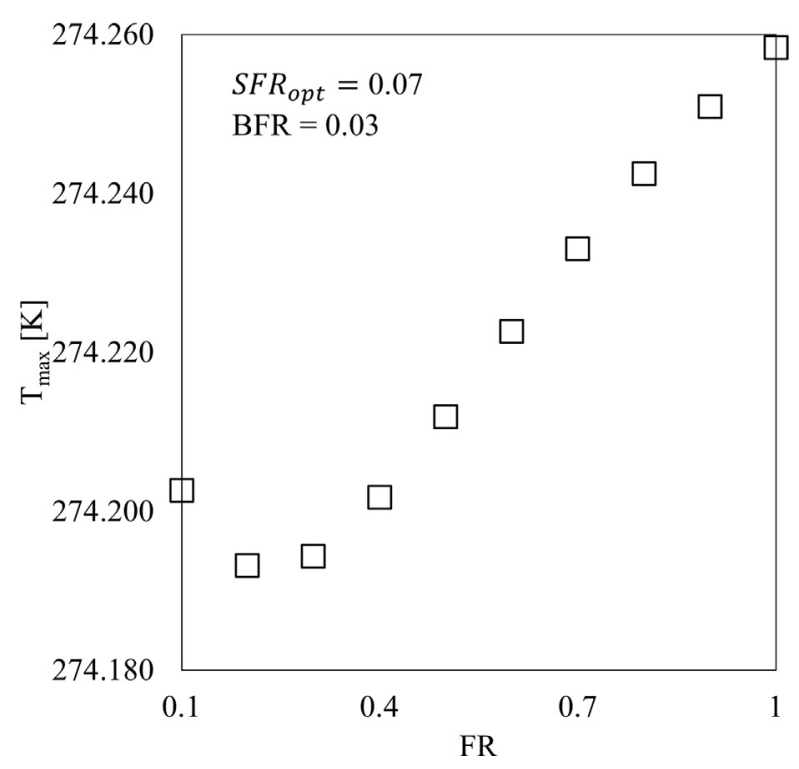

Fig. 10. $T_{\max }$ relative to $F R$ for $B F R=0.03$ and $S F R_{o p t}=0.07$.

$F R_{\text {opt }}$ is 0.3 , like one daughter fin addition, and $B F R_{o p t}$ is 0.02 , which is the same for all daughter fin additions.

\subsection{The effect of angle for daughter fins}

In the second assembly the small fins were placed with an angle $\left(\alpha=10^{\circ}\right)$. Next, the effect of angle $\alpha$ on the thermal resistance should be uncovered. Therefore, $\alpha$ was varied in between $10^{\circ}$ and $60^{\circ}$ in order to uncover the design corresponding to the minimum thermal resistance. Fig. 16 shows that the $T_{\max }$ decreases as the $\alpha$ increases from $10^{\circ}$ to $15^{\circ}$. Then, $T_{\max }$ increases as $\alpha$ increases from $15^{\circ}$ to $60^{\circ}$. Fig. 16 indicates that minimum thermal resistance in achieved with $\alpha=15^{\circ}$ when the fin ratios as given in Figs. 13-15.

\subsection{Third assembly}

The results have uncovered that the daughter fins should be attached to the perimeter of the daughter fin in the middle with 


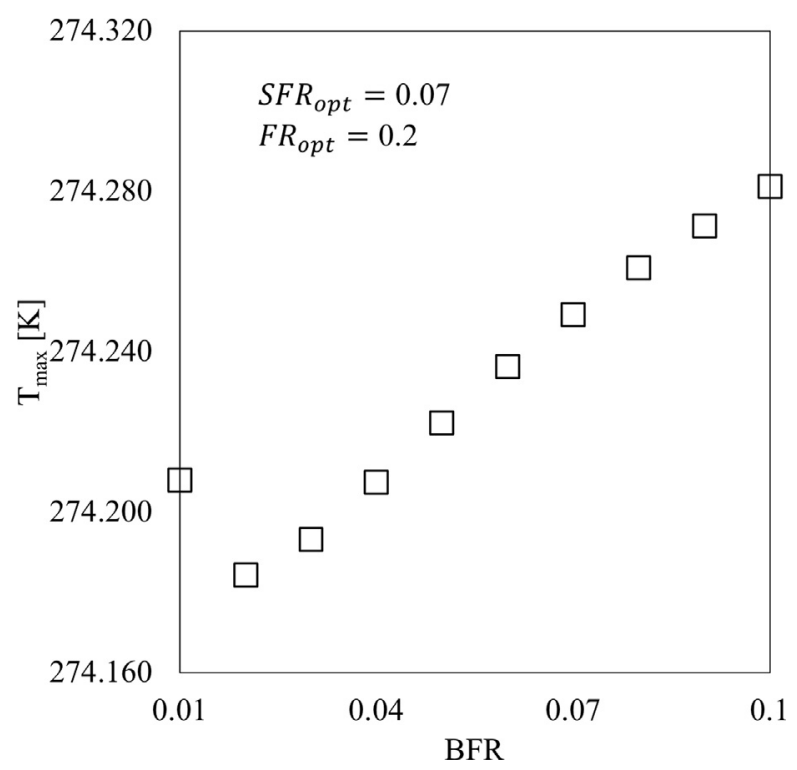

Fig. 11. $T_{\max }$ relative to $B F R$ for $S F R_{o p t}=0.07$ and $F R_{o p t}=0.2$.

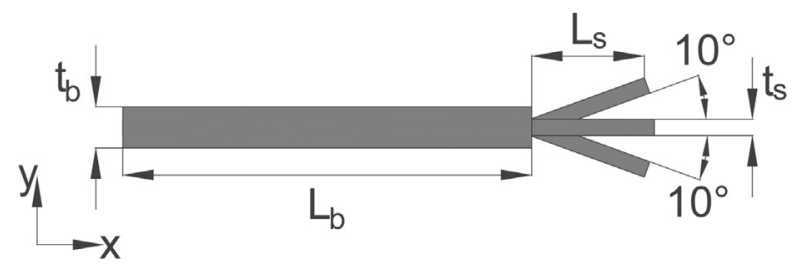

Fig. 12. Placement of the third daughter fin.

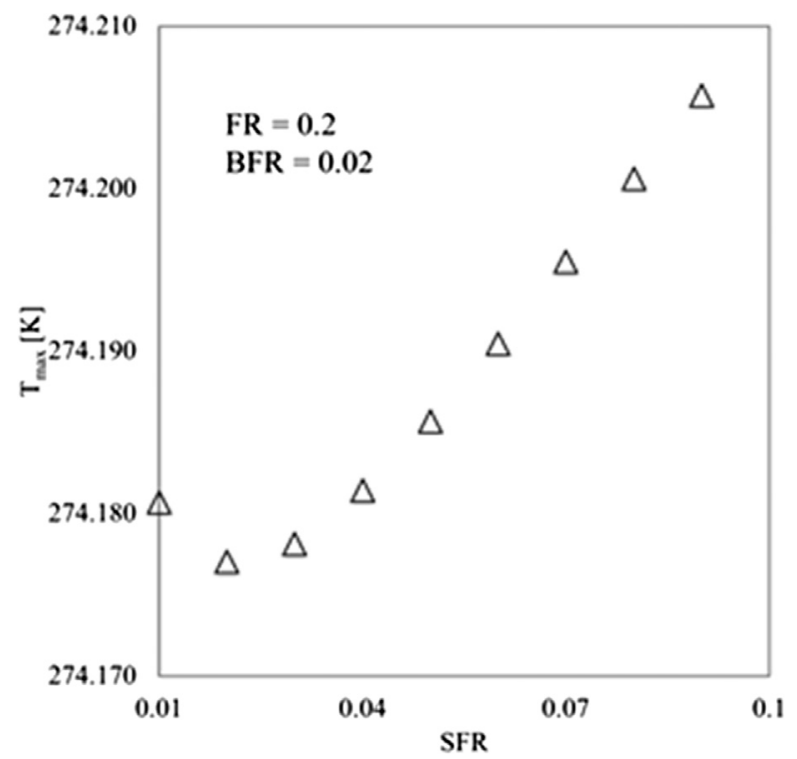

Fig. 13. $T_{\max }$ relative to $\mathrm{SFR}$ for $\mathrm{BFR}=0.02$ and $\mathrm{FR}=0.2$.

an $\alpha_{\text {opt }}$. Next, we use this result to insert new level of daughter fins attached to the perimeter of the mother fins as shown in Fig. 17. The thickness and the length of the new inserts should be bigger than the daughter fins discussed in previous section in order to decrease thermal resistance as mentioned by Ref. [3]. Therefore, the length and thickness of the new addition is $2 \times L_{s}$ and $2 \times t_{s}$, respectively. Furthermore, the results of third assembly also show

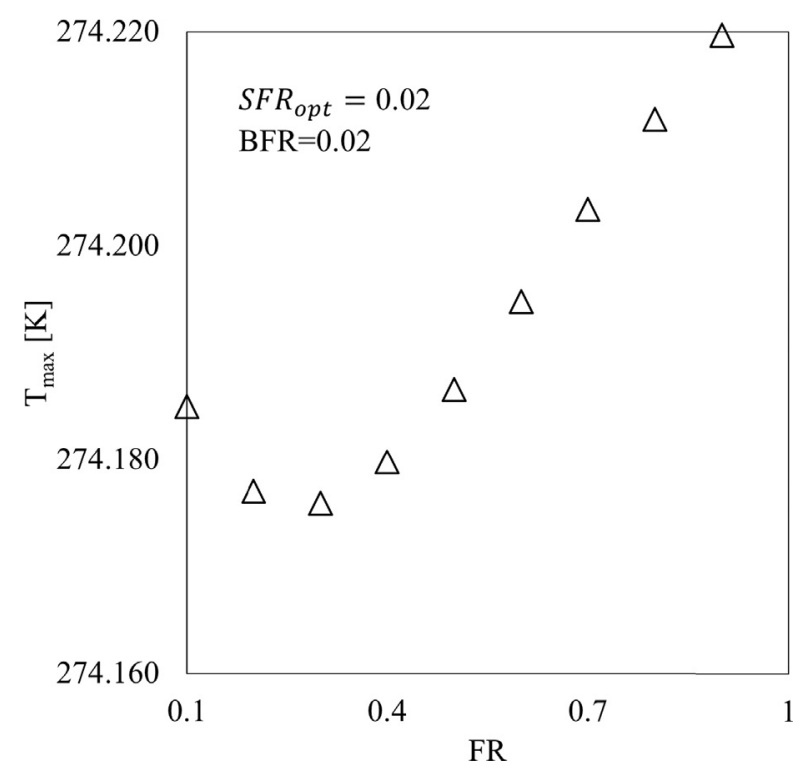

Fig. 14. $T_{\max }$ relative to $\mathrm{FR}$ for $\mathrm{BFR}=0.02$ and $S F R_{o p t}=0.02$.

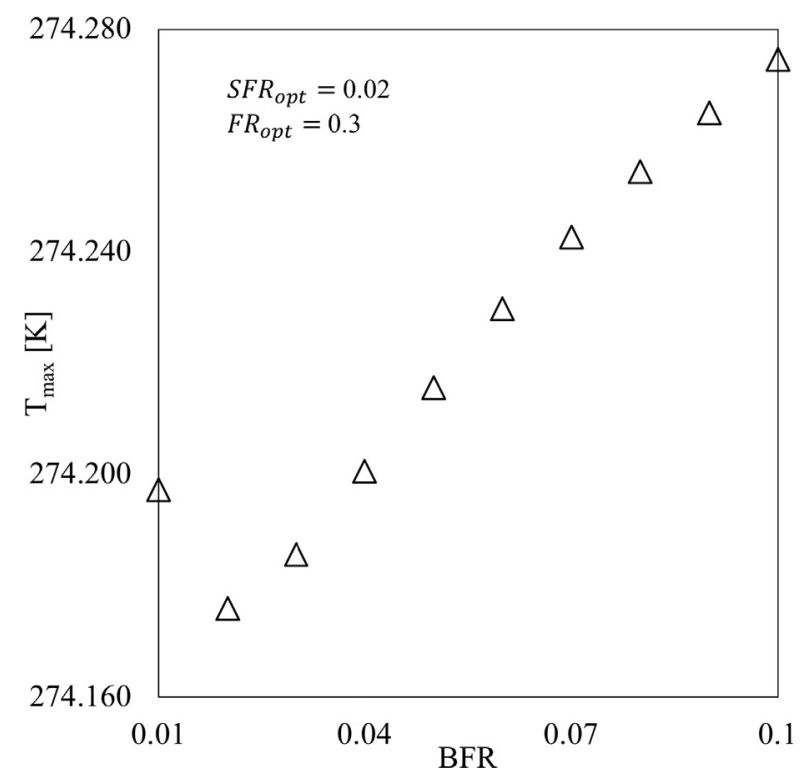

Fig. 15. $T_{\max }$ relative to BFR for $S F R_{\text {opt }}=0.02$ and $F R_{\text {opt }}=0.3$.

that the position of the inserted fins to the perimeter affect the thermal resistance. Therefore, the location of the base of these new additions were varied along the length of the mother fin.

Figs. 18-20 show that how the fin geometric ratios of SFR, FR and BFR affect the $T_{\max }$ when the position of the third assembly is $0.5 \times L_{b}, 0.7 \times L_{b}$, and $0.8 \times L_{b}$. Fig. 18 shows the effect of SFR ratio on the thermal resistance. $T_{\max }$ becomes the minimum with $\mathrm{SFR}=0.02$ for all location of the third assembly base. In addition, the thermal resistance is minimum when the base location of the third assembly is $0.8 \times L_{b}$. Fig. 19 shows the effect of FR ratio on $T_{\max }$ for various locations of the third assembly of fins. $T_{\max }$ is minimum with $\mathrm{FR}=0.4$ when the position is $0.7 \times L_{b}$ and $0.8 \times L_{b}$. However, FR ratio corresponding to the minimum $T_{\max }$ is 0.6 with $0.5 \times L_{b}$ position. Fig. 19 also shows that minimum $T_{\max }$ is achieved when the position is $0.5 \times L_{b}$. Fig. 20 shows the effect of BFR ratio on $T_{\max }$ with the $S F R_{\text {opt }}$ and $F R_{\text {opt }}$ in Figs. 18 and 19. $T_{\max }$ is minimum when position of the third assembly is $0.5 \times L_{b}$ and $\mathrm{SFR}=0.02, \mathrm{FR}=$ 


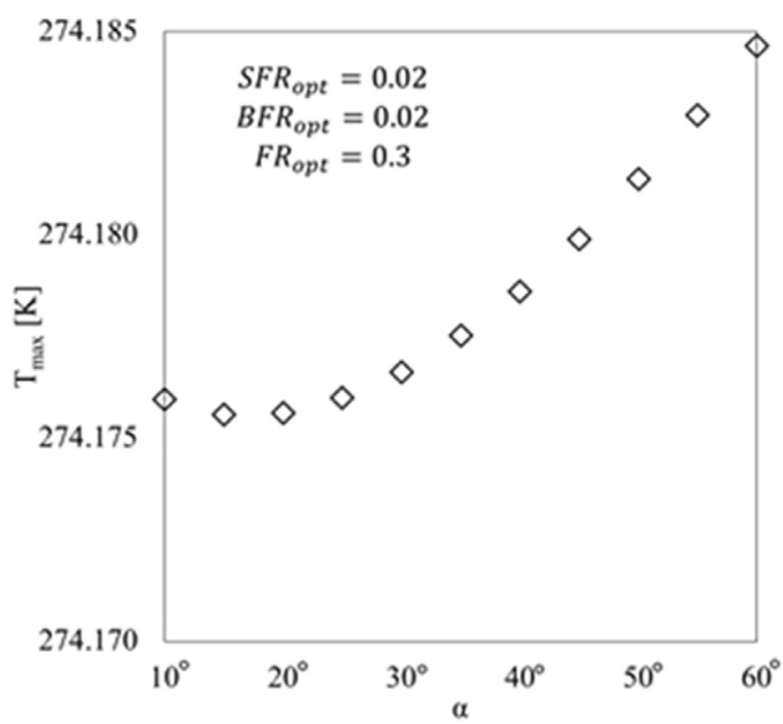

Fig. 16. $T_{\max }$ relative to angle $(\alpha)$.

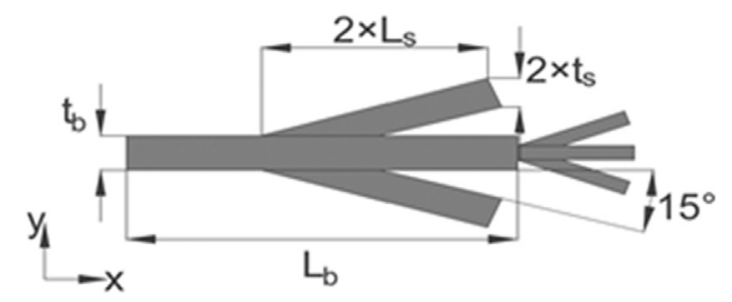

Fig. 17. Placement of the daughter fins in the third assembly.

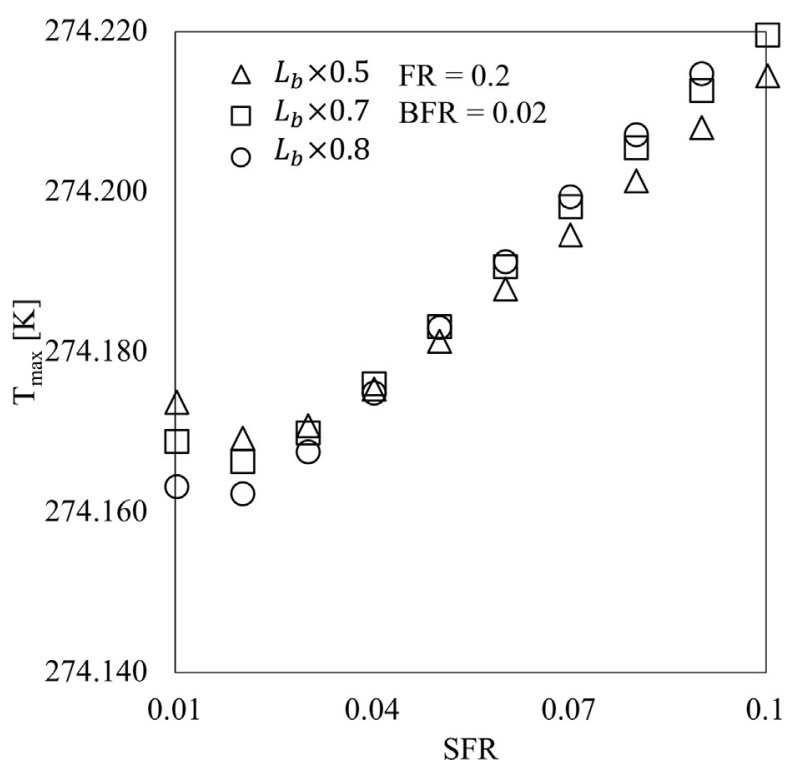

Fig. 18. $T_{\max }$ relative to SFR for various locations of the third assembly when FR= 0.2 and $\mathrm{BFR}=0.02$

0.6 and BFR $=0.03$. Comparison of Figs. 16 and 20 uncovers that the thermal resistance with constructal third assembly becomes smaller than the constructal second assembly design for the constant fin area. Therefore, the results uncover that the thicker fins should be attached to the perimeter of the mother fin and thinner fins should be attached to the perimeter of the daughter fins to decrease the thermal resistance. Furthermore, the comparison of

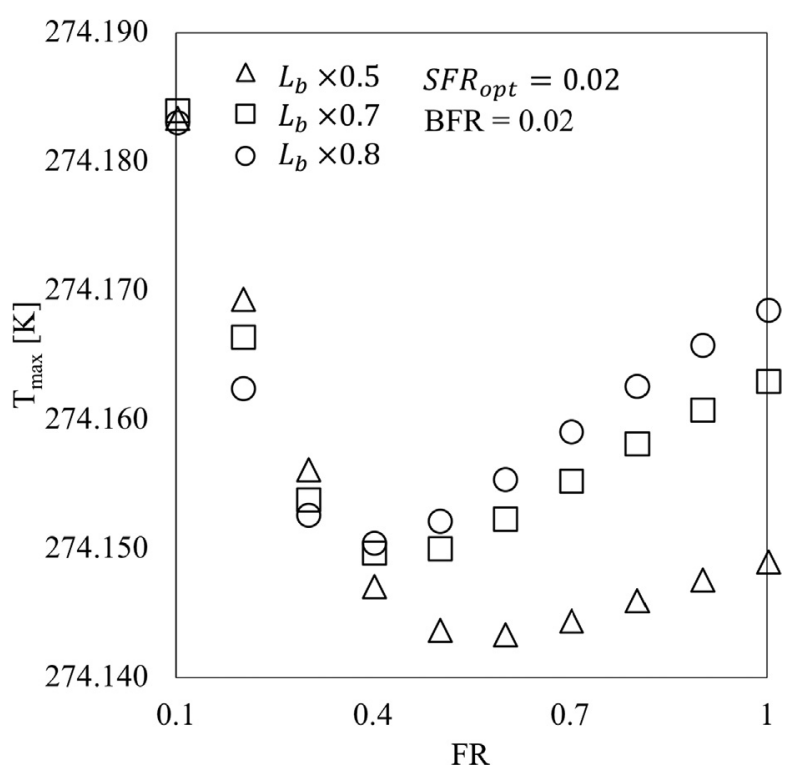

Fig. 19. $T_{\max }$ relative to $F R$ for various locations of the third assembly when $S F R_{\text {opt }}=$ 0.02 and $\mathrm{BFR}=0.02$.

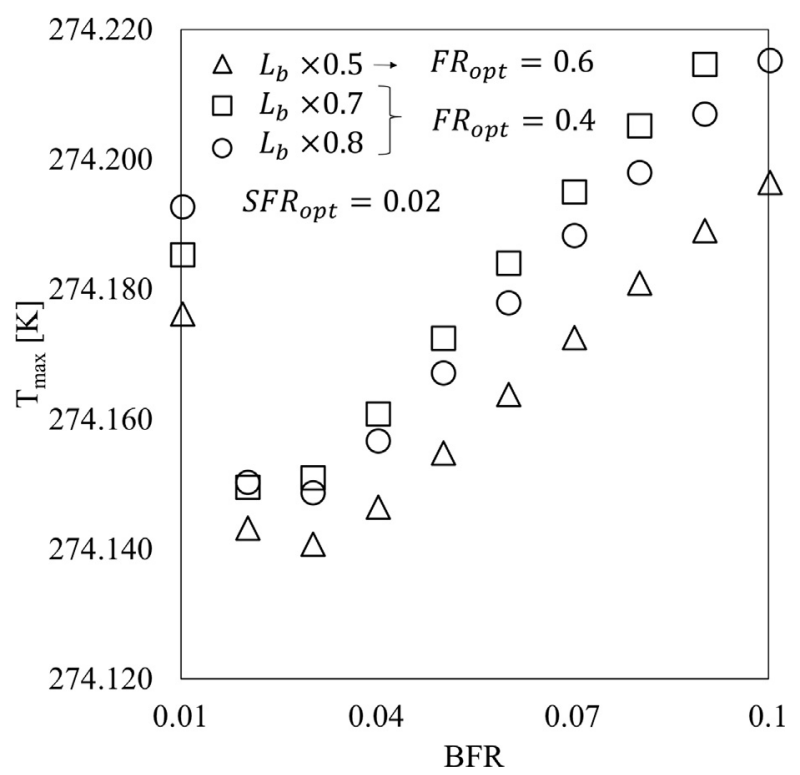

Fig. 20. $T_{\max }$ relative to BFR for various locations of the third assembly when $S F R_{\text {opt }}$ $=0.02$ and $F R_{\text {opt }}=0.4$ and 0.6 .

Figs. 8 and 20 also indicate that the position of the attached fin to the perimeter should be shifted along the length of the mother fin to minimize thermal resistance, i.e. $0.5 \times L_{b}$ and $0.7 \times L_{b}$ are the positions for additional fins to be inserted in order to minimize thermal resistance. The reason for this position shift is related with the growth of the thermal boundary layers. In order to minimize the thermal resistance, the fins should be attached where the domain around the fin is not heated from previous section of assembly. Therefore, the position for the next assembly of the fins should be further from previous section of the fins.

\subsection{Snowflake shaped high-conductivity pathways vs. real snowflake}

After the third assembly, the results indicate that constructal high-conductivity insert is a snowflake, as shown in Fig. 21a. 


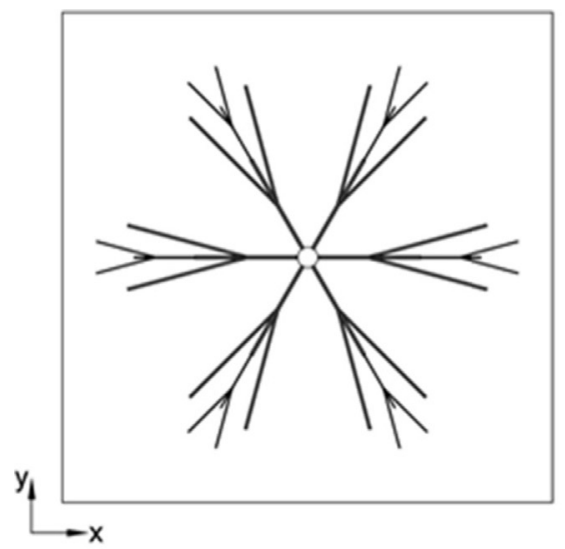

(a)

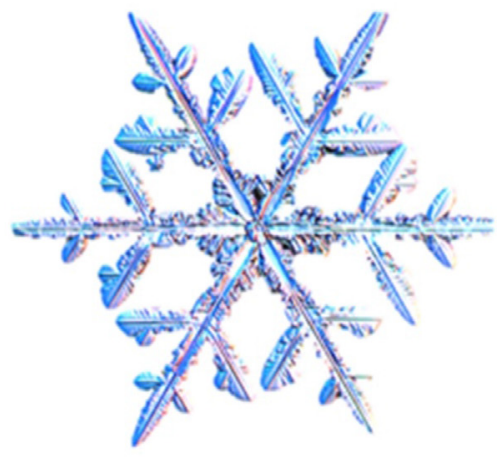

(b)

Fig. 21. (a) The constructal geometry with a point heat source; (b) The real snowflake shape similar to constructal geometry [38]

Mother and daughter fins were placed at to the locations corresponding to the minimum peak temperature. The configuration includes 6 number of mother fins and 30 number of daughter fins. The mother fins are identical. However, all daughter fins are not the same. The daughter fins at the perimeter of the mother fins are larger than the daughter fins at the perimeter of the daughter fins. In addition, Fig. 21b shows a specific snowflake shape. Comparison of the constructal configuration and real snowflake as shown in Fig. 21a and b, it is obvious that the pathways near the center is thicker than the ones further and at the tip. In addition, both designs show that there should be six pathways connected to the center. The constructal configuration of Fig. 21a represents the minimum thermal resistance for a point heat source domain. Therefore, it is clear that snowflake shape is the design corresponding to the minimum resistance to the flow of heat for point to volume flows.

\subsection{The effect of heat flux}

In order to uncover the effect of heat flux on $S F R_{o p t}, F R_{o p t}$ and $B F R_{o p t}$, three distinct heat flux values were also studied such as 3 ,

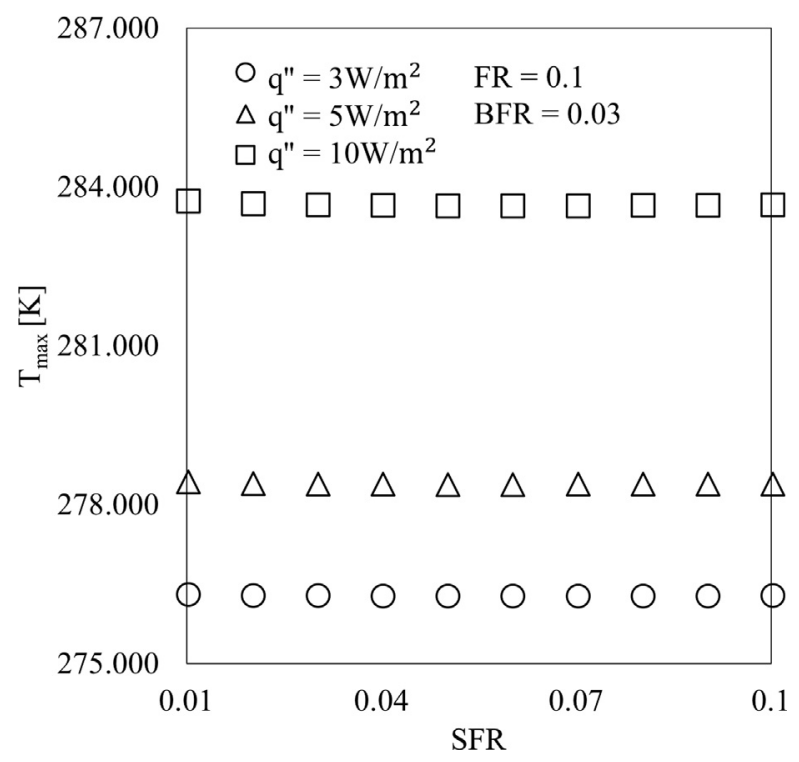

Fig. 22. $T_{\max }$ relative to SFR for $q^{\prime \prime}=3,5$ and $10 \mathrm{~W} / \mathrm{m}^{2}$.
5 and $10 \mathrm{~W} / \mathrm{m}^{2}$. Figs. 22-24 show the effect of fin geometry ratios on $T_{\max }$ for various heat flux values supplied from the perimeter of the heat source as shown in Fig. 1. The results of Figs. 22-24 show that the ratios corresponding to the minimum thermal resistance becomes different than the previous cases, $q^{\prime \prime}=1 \mathrm{~W} / \mathrm{m}^{2}$, as the heat flux value increases. This is expected because there are many distinct shapes of snowflakes. The results confirm that each snowflake shape in the nature corresponds to the minimization of thermal resistance and their shape is different due to the boundary conditions they had while they were being formed.

\subsection{The effect of thermal conductivity}

In this section the effect of thermal conductivity was analyzed. The ratio of thermal conductivities $k$ was varied in order to uncover its effect on the geometry. Figs. 25-27 document the geometric parameters corresponding to the minimum $T_{\max }$ such as, $S F R_{o p t}$, $F R_{\text {opt }}$ and $B F R_{\text {opt }}$. SFR opt is 0.06 and $F R_{\text {opt }}$ is 0.2 when $k$ is varying from 50,80 to 100 . However, when $k$ becomes 200 and more, $S F R_{\text {opt }}$ decreases to 0.05 and 0.03 , respectively. The order of $F R_{o p t}$ is

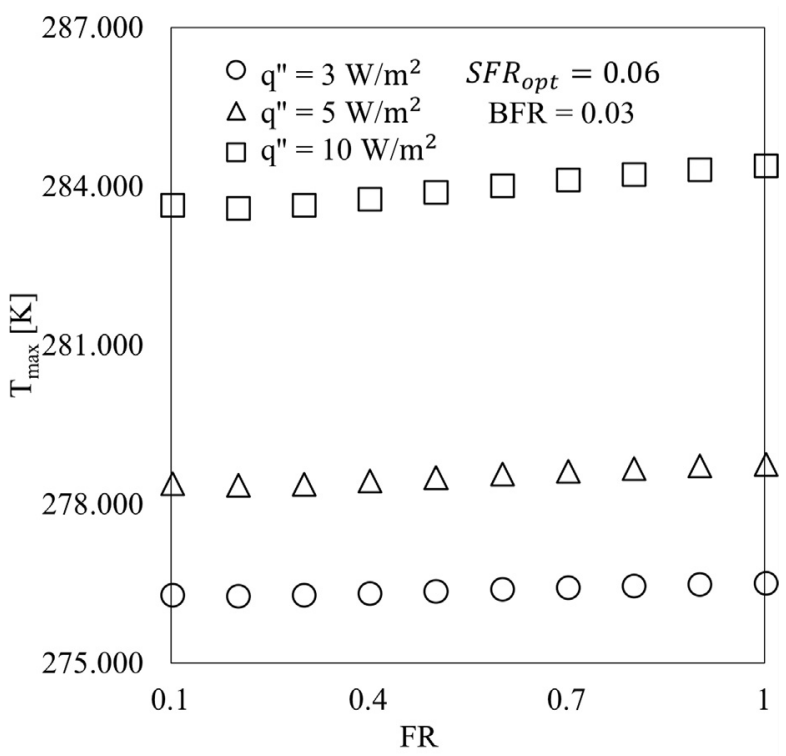

Fig. 23. $T_{\max }$ relative to FR for $q^{\prime \prime}=3,5$ and $10 \mathrm{~W} / \mathrm{m}^{2}$. 


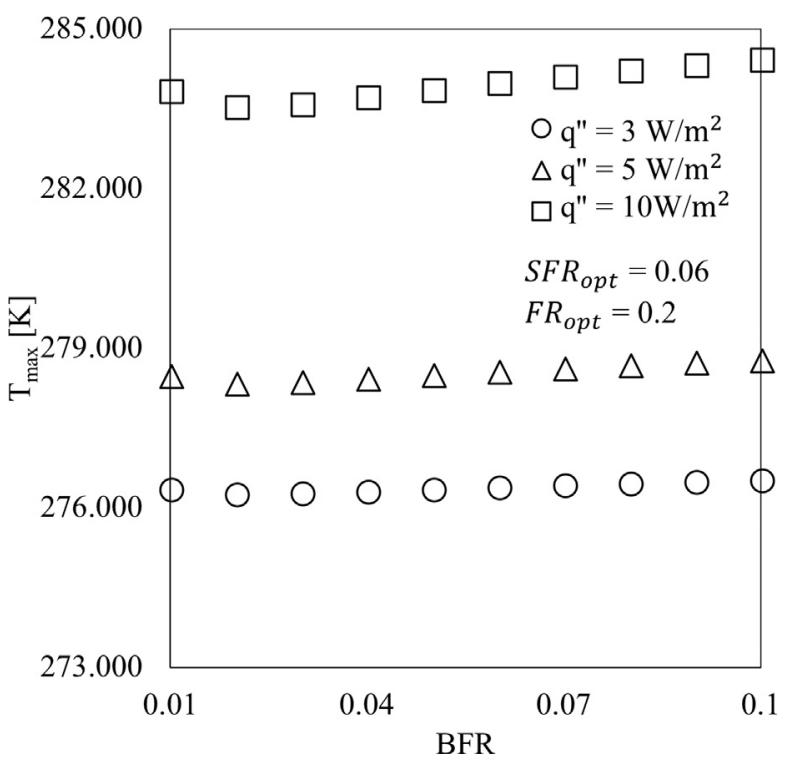

Fig. 24. $T_{\max }$ relative to BFR for $q^{\prime \prime}=3,5$ and $10 \mathrm{~W} / \mathrm{m}^{2}$.

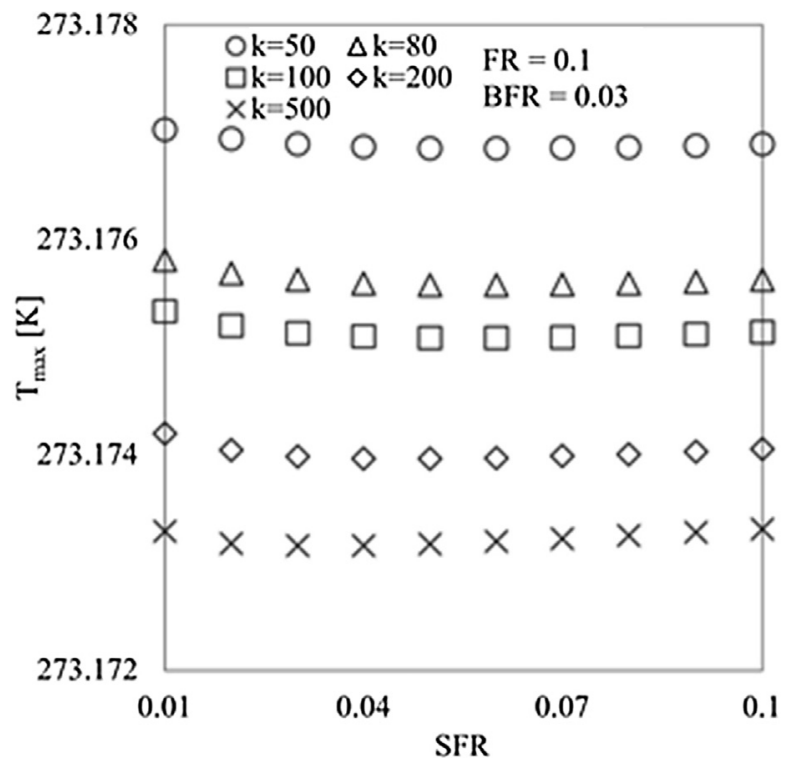

Fig. 25. $T_{\max }$ relative to SFR for $\mathrm{k}=50,80,100,200$ and 500 .

approximately the same $(0.2$ and 0.3$)$ when $k$ varies. In addition, Fig. 27 shows that $B F R_{\text {opt }}$ values exist for $k=50,80$ and 100 . However, there are no $B F R_{\text {opt }}$ when $k=200$ and greater.

\section{Conclusion}

Here, we show that the design of high-conductivity pathways should be similar to snowflakes in designs where a point heat source exists at the center. High-conductivity pathways (rectangular fins) were placed at the perimeter of the heat source in order to minimize excess maximum temperature $\left(T_{\max }\right)$. The geometry of high-conductivity pathways was designed with the guidance of Constructal Theory. First, the geometry of mother fins was uncovered in the first assembly. For mother fin geometry, $\phi=\left(A_{f} / A_{s}\right)$ was varied from 0.001 to 0.01 where fin ratio $\left(t_{f} / L_{f}=0.1\right)$ was constant. Fig. 2 indicates the $T_{\max }$ relation with area fraction when number of fins vary, and it uncovers the two extrema. The first

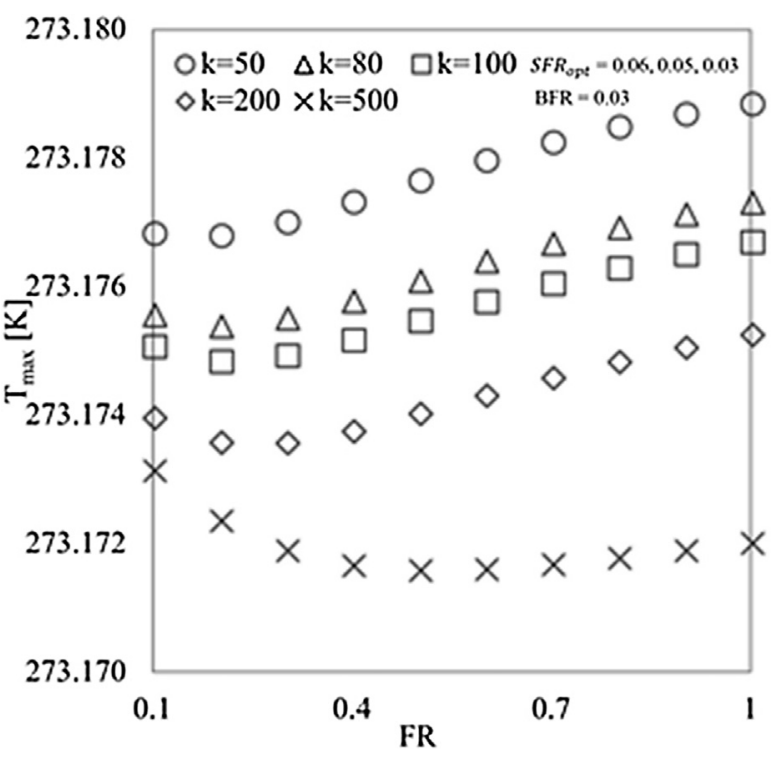

Fig. 26. $T_{\max }$ relative to $\mathrm{FR}$ for $\mathrm{k}=50,80,100,200$ and 500 .

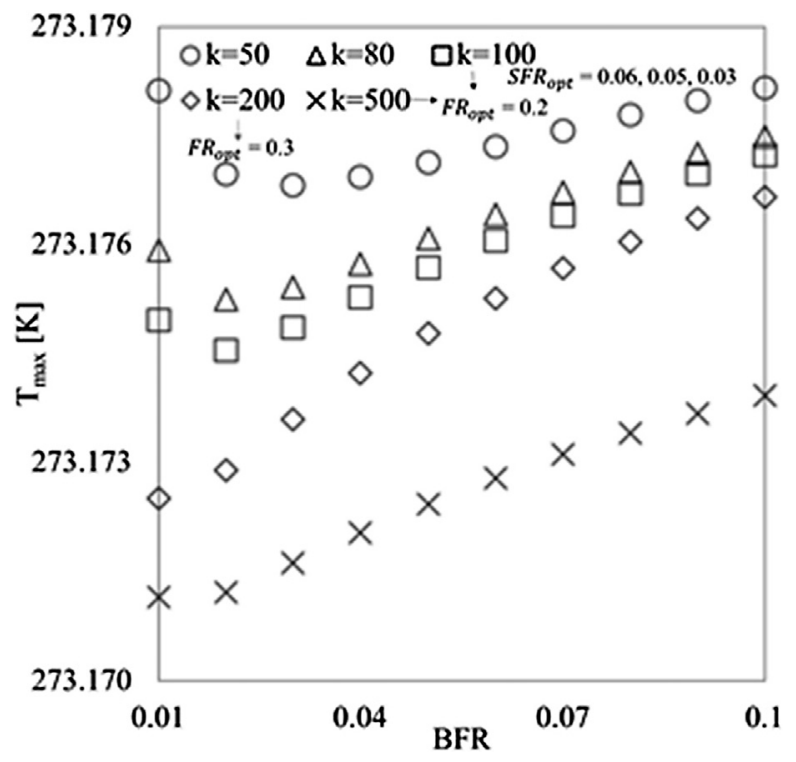

Fig. 27. $T_{\max }$ relative to $B F R$ for $\mathrm{k}=50,80,100,200$ and 500 .

extremum is that $T_{\max }$ exists when the number of fins is low because of large spacing between the fins. The second extremum is that short spacing between fins results in overlapping thermal boundary layer, so heat transfer rate decreases. As shown in Fig. 2, when $\phi<0.004$, minimum $T_{\max }$ exists for 8 number of fins, but when $\phi>0.004$, minimum $T_{\max }$ exists for 6 number of fins. Three distinct fin ratios, SFR $\left(t_{s} / L_{s}\right), \operatorname{FR}\left(L_{s} / L_{b}\right)$ and BFR $\left(t_{b} / L_{b}\right)$, were defined in order to obtain length scales of fins and the number of daughter fins. There are 3 steps for daughter fins addition. In each step one daughter fin was added, and fin ratios were documented. When the number of daughter fins is increased, $S F R_{\text {opt }}$ decreases, which means daughter fins become thinner. In addition, the number of daughter fins does not affect $F R_{o p t}$, so ratio between daughter and mother fins is constant. Similarly, $B F R_{o p t}$ is independent from the number of daughter fins. In addition, daughter fin location $\left(0.7 \times L_{s}\right)$ and angle $\alpha\left(15^{\circ}\right)$ corresponding to the minimum peak temperature were uncovered. 
Third assembly uncovers that the thermal resistance can be decreased even more with the addition of thicker daughter fins to the periphery of the mother fins. The results indicate that daughter fins tend to form where temperature is higher, and these new daughter fins are longer and thicker than the daughter fins attached to tip of mother fins in the second assembly. Third assembly provides significant reduction in $T_{\max }$.

The effect of heat flux on the fin ratios were uncovered by varying the its rate. The results show that the design corresponding to the minimum $T_{\max }$ (minimum thermal resistance) varies as the heat flux varies. This condition is coherent with snowflake formation because each snowflake shape is unique (subjected to different boundary conditions). In addition, the effect of thermal conductivity on the geometry was analyzed by using various thermal conductivity $(k)$ values. The results show that $k$ has also an effect on fin ratios. The results show that when the $k$ is in between 50 and 100 , there is no change for fin ratios, except $B F R_{o p t}$ for $k=50$. However, when the $k$ is equal to greater than $100, S F R_{o p t}$ begins to decrease. However, $F R_{\text {opt }}$ is approximately the same, and it is 0.2 .

The configuration corresponding to the minimum $T_{\max }$ for the given boundary conditions and for point to volume flow is uncovered to be as snowflake shaped. In this study we reduced the thermal resistance by embedded high-conductivity material (rectangular fin) for a domain in which includes a point heat source. Here, the snowflake design was not dictated but uncovered as the design with minimum thermal resistance. The results show that snowflake designs are good distributors and collectors for point to volume flows. Coincidentally, perhaps, this numerical work illustrates convincingly why real snowflakes are shaped the way they are. Snowflakes (Fig. 21b) are the same heat-flow system as the uncovered constructal design of Fig. 21a. Snowflakes spread the latent heat of solidification into the interstices between their needles, just like the inserts constructed in (a). The results of the current study also in agreement with Constructal Theory and where the design should freely be altered to provide the smallest resistance to the flow as the conditions vary.

\section{Conflict of interest}

The authors declared that there is no conflict of interest.

\section{Appendix A. Supplementary material}

Supplementary data associated with this article can be found, in the online version, at https://doi.org/10.1016/j.ijheatmasstransfer. 2018.08.063.

\section{References}

[1] S. Kakaç, H. Yüncü, K. Hijikata, Cooling of Electronic Systems, Kluwer Academic Publishers, Dordrecht, 1994.

[2] A. Bejan, Constructal theory network of conducting paths for cooling a heat generating volume, Int. J. Heat Mass Transf. 40 (1997) 799-816.

[3] A. Bejan, S. Lorente, Design with Constructal Theory, John Wiley \& Sons Inc, New Jersey, 2008.

[4] A. Bejan, V. Badescu, A. De Vos, Constructal theory of economics structure generation in space and time, Energy Convers. Manage. 41 (2000) 1429-1451.

[5] A.H. Reis, A.F. Miguel, M. Aydın, Constructal theory of flow architecture of the lungs, Med. Phys. 31 (2004) 1135-1140.

[6] A. Bejan, S. Lorente, Constructal theory of generation of configuration in nature and engineering, J. Appl. Phys. 100 (2006).

[7] A.V. Azad, M. Amidpour, Economic optimization of shell and tube heat exchanger based on constructal theory, Energy 36 (2011) 1087-1096.

[8] G.A. Ledezma, A. Bejan, M. Errera, Constructal tree networks for heat transfer, J. Appl. Phys. 82 (1997) 89-100.

[9] A. Bejan, M. Almogbel, Conduction trees with spacing at the tips, Int. J. Heat Mass Transf. 42 (1999) 3739-3756.
[10] E. Cetkin, A. Oliani, The natural emergence of asymmetric tree-shaped pathways for cooling of a non-uniformly heated domain, J. Appl. Phys. (2015) 118

[11] G. Lorenzini, C. Biserni, L.A.O. Rocha, Constructal design of non-uniform Xshaped conductive pathways for cooling, Int. J. Therm. Sci. 71 (2013) 140-147.

[12] M.R. Hajmohammadi, V.A. Abianeh, M. Moezzinajafabadi, M. Daneshi, Forkshaped highly conductive pathways for maximum cooling in a heat generating piece, Appl. Therm. Eng. 61 (2013) 228-235.

[13] M.R. Hajmohammadi, O.J. Shariatzadeh, M. Moulod, S.S. Nourazar, Phi and Psi shaped conductive routes for improved cooling in a heat generating piece, Int. J. Therm. Sci. 77 (2014) 66-74.

[14] M.R. Hajmohammadi, G. Lorenzini, O.J. Shariatzadeh, C. Biserni, Evaluation in the design of $\mathrm{V}$-shaped highly conductive pathways embedded in a heatgenerating place, J. Heat Transfer 137 (2015).

[15] C.D.S. Horbach, E.D. dos Santos, L.A. Isoldi, L.A.O. Rocha, Constructal design of Y-shaped conductive pathways for cooling a heat generating body, Defect and Diffusion Forum, vol. 358, Trans Tech Publications, Switzerland, 2014, pp. 245260 .

[16] H. Feng, L. Chen, Z. Xie, F. Sun, Constructal design for "+" shaped high conductivity pathways over a square body, Int. J. Heat Mass Transf. 91 (2015) 162-169.

[17] M. Eslami, Optimal conductive constructal configurations with "parallel design", Energy Convers. Manage. 111 (2016) 352-357.

[18] J. You, H. Feng, L. Chen, Z. Xie, Heat conduction constructal optimization for nonuniform heat generating area based on triangular element, Int. J. Heat Mass Transf. 117 (2018) 896-902.

[19] G. Lorenzini, E.X. Barreto, C.C. Beckel, P.S. Schneider, L.A. Isoldi, E.D. dos Santos, L.A.O. Rocha, Constructal design of I-shaped high conductive pathway for cooling a heat-generating medium considering the thermal contact resistance, Int. J. Heat Mass Transf. 93 (2016) 770-777.

[20] G. Lorenzini, E.X. Barreto, C.C. Beckel, P.S. Schneider, L.A. Isoldi, E.D. dos Santos, L.A.O. Rocha, Geometrical evaluation of T-shaped high conductive pathway with thermal contact resistance for cooling of heat-generating medium, Int. J. Heat Mass Transf. 2017 (2017) 1884-1893.

[21] C. Biserni, L.A.O. Rocha, A. Bejan, Inverted fins: geometric optimization of the intrusion into a conducting wall, Int. J. Heat Mass Transf. 47 (2004) $2577-$ 2586.

[22] G. Lorenzini, L.A.O. Rocha, Constructal design of Y-shaped assembly of fins, Int. J. Heat Mass Transf. 49 (2006) 4552-4557.

[23] G. Lorenzini, S. Moretti, Numerical analysis on heat removal form Y-shaped fins: efficiency and volume occupied for a new approach to performance optimisation, Int. J. Therm. Sci. 46 (2007) 573-579.

[24] Z. Xie, L. Chen, F. Sun, Constructal optimization of twice Y-shaped assemblies of fins by taking maximum thermal resistance minimization as objective, Sci. China Technol. Sci. 53 (2010) 2756-2764.

[25] G. Lorenzini, C. Biserni, R.L. Correa, E.D. dos Santos, L.A. Isoldi, L.A.O. Rocha, Constructal design of T-shaped assemblies of fins cooling a cylindrical solid body, Int. J. Therm. Sci. 83 (2014) 96-103.

[26] E. Cetkin, Inverted fins for cooling of a non-unifomly heated domain, J. Therm. Eng. 1 (2015) 1-9.

[27] H. Feng, L. Chen, Z. Xie, F. Sun, Constructal design for helm-shaped fin with internal heat sources, Int. J. Heat Mass Transf. 110 (2017) 1-6.

[28] D. Conners, How snowflakes get their shape, Retrieved May 2018, from EarthSky: <http://earthsky.org/earth/how-do-snowflakes-get-their-shape>, 2018.

[29] K. Kikuchi, T. Kameda, K. Higuchi, A. Yamashita, A global classification of snow crystals, ice crystals and solid precipitation based on observations from middle latitudes to polar regions, Atmos. Res. 132-133 (2013) 460-472.

[30] J. Tyynela, J. Leinonen, D. Moisseev, T. Nousiainen, Radar Backscattering from Snowflakes: comparison of fractal, aggregate and soft spheroid models, J. Atmos. Oceanic Technol. 28 (2011) 1365-1372.

[31] H. Nowell, G. Liu, R. Honeyager, Modeling the microwave single-scattering properties of aggregate snowflakes, J. Geophys. Res.: Atmos. 118 (2013) 78737885.

[32] R. Albanese, R. Ambrosino, M. Mattei, A procedure for the design of snowflake magnetic configurations in tokamaks, Plasma Phys. Control. Fusion 56 (2014).

[33] D.K. Lee, C.W. Ahn, H.J. Jeon, Web of carbon fibers coated with 3D snowflakeshaped Ni3S2/Ni produced by electroless Ni plating: a binder-free cathode electrode for lithium batteries, Microelectonic Eng. 166 (2016) 1-4.

[34] A. Bejan, S. Lorente, B.S. Yilbas, A.Z. Sahin, Why solidification has an S-shaped history, Nat. Sci. Rep. 3 (2013) 1711, https://doi.org/10.1038/srep01711.

[35] COMSOL Multiphysics 5.0, COMSOL Inc, 2014.

[36] L.A.O. Rocha, S. Lorente, A. Bejan, Conduction tree networks with loops for cooling a heat generating volume, Int. J. Heat Mass Transf. 49 (2006) $2626-$ 2635.

[37] A.L. Razera, R.J.C. da Fonseca, L.A. Isoldi, E.D. dos Santos, L.A.O. Rocha, C. Biserni, Constructal design of a semi-elliptical fin inserted in a lid-driven square cavity with mixed convection, Int. J. Heat Mass Transf. 126 Part B (2018) 81-94.

[38] K.G. Libbrecht, Snow Crystals, Retrieved May 2018, from Snow Crystals.com: <http://snowcrystals.com/>, 1999. 